\title{
Coping strategy based on socio-agriculture approach in Landslide Prone Area in the Gede Catchment, Malang Regency
}

\author{
Aulia Rahman Oktaviansyah \\ Wisnuwardhana University of Malang, Indonesia
}

Nurul Muddarisna, Heni Masruroh* \& Eny Dyah Yuniwati

Agriculture Faculty, Wisnuwardhana University of Malang, Indonesia

\begin{abstract}
The aim of this paper is to elaborate the copy strategy using socio-agriculture by the community for living harmony in a high potential landslide area. The method was carried out by field survey and deep interview regarding the community's coping strategy using socio agriculture and the agriculture system. A field survey was done using a grounded research technique. Based on the data shows that the community of Gede Catchment has a coping strategy for living harmony using socio-agriculture. The community has local indigenous value to mitigate the impact of landslide disaster. They have a high tolerance for each other not only when disaster occurs but in daily activities. The community uses the former landslide to plant vegetable crops. The community has a coping strategy for arrangement their environment between permanent tress and vegetables crops in the each single topography as control landslide. It is this coping strategy to mitigate the landslide disaster because with high tolerance and arrangement the spatial arrangement of plants and topography can decrease the chance of a landslide disaster.
\end{abstract}

Keywords: agriculture, disaster, community

\section{INTRODUCTION}

Based on the data types of Disaster which occurred in Indonesia, the number of landslide disasters is the second-ranked after a forest fire disaster. In the year 2019, there were 1.483 landslide disaster occurrences (BNPB 2020). A landslide is the process of soil movements with a sloping direction from its original position and separated from a stable mass due to the influence of gravity. Mostly landslides will occur in the mountainous and hilly areas with thick soil. Landslide events usually occur during the peak of wet season and in the hilly areas (Igwe 2015). Geomorphology is the one of factors that affects landslide occurrence. But sometimes, landslides can occurr by accelerating community activities who manage their environment improperly (Skilodimou et al. 2018; Barnard et al. 2001; Zhang et al. 2012). Sometimes, the community manages their environment and neglects the soil characteristic. This will increase the landslide potential (Muddarisna et al. 2019).

Landslide disasters are the most common disaster types in Indonesia. The potential of landslides will be higher when the communities don't conserve their environment and the communities are rising. Generally, landslides will occur in the rough geomorphology. To prevent landslides, the communities has to consider the soil characteristic to determine the type of mitigation which will reduce the landslide risk disaster chances. Improper mitigation which had been done by the communities without paying attention to soil characteristics will increase the landslide potential. Generally, the communities will use woody plants to reduce landslides. Even though in the thick

*Corresponding author: henimasruroh11@gmail.com 
soil conditions, woody plants are not proper for decreasing landslide potential. The woody plant will increase the soil mass, Thus the land-slide potential will increase also. Landslide conservation without considering the soil condition will trigger a landslide. Sometimes to reduce the risk of landslides, optimizing the local wisdom of the community in the social aspects and ways of the community in managing their environment, including managing their agricultural systems can be performed. This is called community coping capacity and is an effort to reduce the risk of landslides.

The impact of landslide disaster is varied between each landslide prone area (Tjah-jono et al. 2018; Setyono et al. 2005). It depends on the condition of environmental vulnerability and the coping capacity of communities to manage their environment and their local knowledge. If the risk element has a low vulnerability value, and the community has good coping capacity, the disaster risk can be minimized. The coping capacity is regarding the social aspect and managing the agriculture system. The social aspect is regarding gender, age, occupation and also some other local wisdom related to communities social relation ships which had been applied in an area when disasters occur. For instance, there are regular local meetings to discuss landslide disaster risks or there is a community in an area which focuses on reducing the landslide disaster risk. How to manage agricultural land in areas prone to landslides is also important and can be considered an effort to reduce landslide risk. Most of the landslides occur in agricultural areas with various types of crops. If the plantation and managing agricultural land is not appropriate with soil conditions, it can trigger landslides. On the other hand, if managing agricultural land and the plantation is proper with the land, it can be an effort to reduce the potential of landslides. Both of them can be coping strategies for the community in landslide prone areas.

Humans or society in the context of a disaster are the object as well as the subject of the disaster itself. They not only deal with the pre-disaster threat, but also take the risk of losing lives due to the disaster, and still have to face the post-disaster conditions. Therefore, there needs to be an effort to improve the ability or capacity of the society in facing disaster. The coping capacity, which is focusing on the social-agriculture aspect, is still rare (Rieux, Karen, Jaquet, Stephanie, Derron, Henri, Jaboyedoff 2012; Bohle \& Adhikari 1998; Gurung 1989). The research objective of this research is to elaborate the coping strategies of society based on the socio-agriculture aspect in the Gede Catchment.

Gede Catchment is the upper part of Bromo Mountain. It is located in the Malang Regency, East Java province. Mostly, the land use of this area is agriculture with several crop plantations in every single topography. The subsurface material is dominated by deposition of Bromo Volcano material i.e andesitic, basalt, tephra, alluvium, young material Bromo Volcano, and limestone.

\section{METHOD}

The data used in this research is DEMNAS data for making the landslide susceptibility map. It is created by a geomorphometric approach which several steps: 1) DEM download processing; 2) DEM processing analysis; 3) Landslide susceptibility map processing using thematic map analysis; 4) field check; 5) re-interpretation; and 6) layout land-slide susceptibility map. DEM analysis data was done by Integrated and Water Information System Software (ILWIS).

The field survey was done for accuracy of landslide susceptibility maps, observation and a deep interview with society regarding the socio-agriculture system which applies in this research area. The field survey and observation is including the condition of social aspects when the disaster occurs and the kind of the plantation which planted in this area as an effort to control and mitigation landslides. The social aspect is also including observation the community behaviour in their environment including planting and harvesting their agriculture. The field survey is also completed with the purposive in-depth interview of community.

The result of this research is focused on elaborating the formula of socio-agriculture systems in the community as a coping strategy as control and landslide mitigation. The scientific explanation based on the real conditions. We found the several fact that socio-agriculture which had been applying in the research area has a positive impact as a coping strategy. 


\section{RESULTS AND DISCUSSION}

\subsection{Landslide susceptibility analysis}

A landslide is a natural disaster which has a characterization that includes its physio-graphic characteristics. Landslide susceptibility can be analyzed based on several factors. The landslide inventory can be collected by field surveys and analyzing remote sensing data. Landslide susceptibility mapping is producing in this research based on the analysis of remote sensing data and field survey as an accuracy check. The landslide disasters are influenced by several factors causing a landslide, i.e. elevation, slope, topographic position index, curvature, plan curvature, and profile curvature. Each factor can cause soil material movement.

Based on the landslide susceptibility mapping shows that this area has a high potential of landslide around $52.9 \%$, middle potential landslide $30.5 \%$ and low potential landslide around $16.6 \%$. The landslide has become an environmental problem in this area. There were several landslides which had occurred, and they damaged the agricultural land, roads and settlements. The typology of a landslide in this area is a rotational landslide and is translational. Each typology landslide has its own characteristics. Both active and inactive landslides are used for agricultural crop cultivation.

Based on the landslide susceptibility mapping, this area consists of a stable zone such as the landslide area and an unstable zone. The stable zone is in the peak interfluves and foot slope. Both of them have a low slope, thus, there is no energy to move the soil material. Whereas, for the unstable zone, it started from the upper slope and went until the lower slope. The topographic position of the slope is started from peak interfluves until the channel was bad. Soil material starts to move in the topographic position of the upper slope. The geomorphological processes found on the upper slope as an indicator of the movement of soil material is the presence of cracks (soil cracks) and erosion. Both geomorphological processes can initiate the movement of soil material, so that it can initiate material movements (Samodra 2014). The topographic position of the slope that has no force to move the material, namely alluvial and colluvial plains. The topography of the Gede Catchment is largely unstable because of slope cutting for road and river

\subsection{Socio-agriculture as a coping strategy for landslide susceptibility}

Capacity is elaborated as a combination of all strengths existing in a community, society and organization that may reduce the impact of disaster risk. Capacity as mitigation of disaster risk can be structural and non-structural capacity. Mostly, several areas which have disaster risks use structural mitigation as a coping strategy. Non-structural mitigation is still rarely done by the community. The capacity is not only for reducing the disaster risk, but it is also to develop a safety culture, to make the community aware, to self-protect and a supporting effort to protect others and society in general.

For the social aspect, the pattern of life and livelihoods of the Gede Catchment communities is harmonious interaction with nature and with each other's communities. The existence of community interaction is to supply all the needs in their daily life. Interaction among people in the Gede Catchment has used a kinship system. The interaction of communities with nature is part of the community's livelihood pattern to survive.

A family system and a culture of mutual assistance emerged because the people of the Gede Catchment lived in areas prone to landslides. The settlement pattern of the Gede Catchment community can be identified based on the interpretation of the Spot 5 imagery. The results of the interpretation of the Spot 5 imagery of the Gede Catchment settlement show that the settlement pattern of the Gede Catchment community is elongated and clustered. The dispersed settlement pattern is located on the outrigger of the Catchment and follows the road network pattern. The clustered settlement pattern is located on the slopes of the foothills. The clustered settlement pattern is an indicator that the Gede Catchment community uses a family system with a culture of helping out. 
The spatial distribution of settlements is close to each other (cluster family system). The communities of Gede Catchment are aware that the Gede Catchment area is an area prone to landslides. Public awareness regarding disasters as evidenced by the existence of relief activities, humanitarian activities and routine activities of the Gede Catchment community. Through these activities, kinship between communities, disaster training, disaster information and other activities related to disaster response can be improved, especially for landslides. Activities have been routinely carried out in the Gede Catchment to teach each other community to be responsive to signs of landslides, actions taken when landslides and actions were taken after landslides occur (Interview at Downstream Gede Catchment Community 2020).

For aspect agriculture, it emphasizes how people manage their agricultural environment. The aspect of agriculture in this area is an important factor that must be considered be-cause most of the land use in this area is agricultural land with seasonal vegetable crops. Planting types of plants that are not suitable for soil conditions can lead to movement of soil material. Efforts to reduce the risk of landslides by planting woody plants in this area are not proper because this area has thick soil. Managing the agricultural system regarding the type of plantation is necessary to reduce the landslide disaster risk because mostly the land use is agricultural.

The communities have a coping strategy regarding agriculture to reduce landslide disaster risk. The communities had been planting their agriculture with mixed crop plantation in each single of topography. Mixed crop plantation can be one of the solutions in environmental management (Zuazo \& Pleguezuelo 2008). This happens because plants are one of the factors that have an influence on soil conditions. This includes influencing the infiltration process, run off and soil mass load. The communities of Gede Catchment practiced the mixed garden for economic income and one of the ways for landslide conservation, particularly vegetative conservation. They assume that a mixed garden is the solution that provides economic and environmental benefits. Gede Catchment's society had been an awareness of living in the study area that has a high potential of landslide. The community is more selective for determining the types of vegetation in each unit morphology and in considering land cultivation and uncultivated land. Both of them have the potential to influence of occurrence of a landslide. The inclination of the slope will be changed if the landslide occurs. It will affect soil erosion, run off and infiltration.

The land utilization in the Gede Catchment shows spatial arrangement based on the physical characteristics in the study area. The spatial arrangement includes the type of vegetation, unit morphology and landslide site. The types of vegetation such as bamboo, clove and other woody plants have been planted in the peak interfluves. The mixed garden such combining of coffee plantation with the holticulture plants such as carrots, apples and potatoes was applied in the upper slope until lower slope. The foot slope was used for seasonal vegetation.

The spatial arrangement also applied in the landslide site. There are differences between spatial arrangements in active landslides and inactive landslides. For the active landslides the type of vegetation is just grown naturally without human planting. It will differ with the inactive landslide. Mostly, the society planted several local agroforestry plantations in the spatial arrangement of the landslide site. At the crown area, the society planted woody plantation such cloves and bamboo. The communities have assumed that these plants could conserve the soil movement.

The socio-agriculture which had been applying in the Gede Catchment as a coping strategy is indicative about how the community attitude is regarding landslide mitigation. In the Gede Catchmentm a family system with a cultural of mutual assistance emerged. The community management system of the Gede Catchment is shown by the location of the settlements between families that are close to each other. The communities of Gede Catchment are aware that the Gede Catchment area is an area prone to landslide. There were several activities which had been applied by the Gede Catchment community to decrease the risk of landslide potential. The activities is tend to public awareness regarding disaster through the existence of relief activities and routine activities i.e. weekly street cleaning and routine check activities to identify land condition which has the potential of landslides. In addition, the community also has the monthly routine agenda for disaster training, an early warning system as disaster information and other things related to disaster 
response especially for landslides. These activities improve the capacity of communities regarding decreasing the risk potential of landslides. These activies teach each other to be responsive to signs of landslides.

\section{CONCLUSSION}

The study area is the mountainous area which has a high potential of landslide. For reducing the landslide disaster risk, the communities of Gede Catchment had been applying the socio-agricultural aspect. The social aspect is tended about the harmony interaction with nature and with each other and with the lives and livelihoods of the Gede Catchment communities. They applied the family system in their daily activities including when the disaster occurs. Whereas, for the agriculture, they applied very appropriate conservation efforts in their agricultural systems with the crop plantation in each unit morphology for reducing the soil movement. The socio-agricultural aspect had been applying in this study area as a coping strategy for reducing landslide disaster risk.

\section{REFERENCES}

Alkhasawneh, M., Umi, K., Lea, T., Nor, A., dan Mohammad, S. (2013). Determination of Important Topographic Factors for Landslide Mapping Analysis Uisng MLP Network. The Scientific World Journal, $1-12$.

Blaga, L. (2012). Aspect Regarding The Significance of the Curavture Types and Values in the Studies of Geomorfometry Assited By GIS. Seria Geografie, 327-337.

Barnard, P.L. et al., 2001. Natural and human-induced landsliding in the Garhwal Himalaya of Northern India. Geomorphology, 40(1-2), pp. 21-35.

BNPB, 2020. Data Bencana, Available at: https://bnpb.cloud/dibi/laporan5 (Accessed, August 26th, 2020).

Bohle, H.-G. \& Adhikari, J., 1998. Rural livelihoods at risk how Nepalese farmers cope with food insecurity. Mountain Research and Development, pp. 321-332.

Gallant, J.C., dan Wilson, J.P. (2000). Primary Topographic Attribut: Terrain Analysis Principles and Application. New York.

Hengl, T., Gruber, S., dan Shresta, D. P. (2003). Geomorphometry in Ilwis: Concept, Software, applications. Development in Soil Science. Elsevier, 497-525.

Igwe, O., 2015. The geotechnical characteristics of landslides on the sedimentary and metamorphic terrains of South-East Nigeria, West Africa. Geoenvironmental Disasters, 2(1), pp. 1-14.

Olaya, V. (2009). Basic Land Surface Parameters. Application Developments in Soil Science, 141-169.

Reneau, S. L., dan Dietrich, W. E. (1987). The Importance of Hollows in Debris Flow Studies; Examples from Marin Country, California. Engineering Geology, 165-180.

Rieux, Karen, Jaquet, Stephanie, Derron, Henri, Jaboyedoff, M., 2012. A case study of coping strategies and landslides in two villages of Central-Eastern Nepal. Applied Geography, 32(2), pp. 680-690.

S.M, G. (1989). Human Perception of Mountains Hazard in the Kakani Kathmandu Area: Experience from The Middel Mountains of Nepal. Mountains Researcg and Development, 353-364.

Samodra, G., 2014. DEVELOPMENT OF RISK ANALYSIS TECHNIQUE AND ITS APPLICATION TO GEO-DISASTER MANAGEMENT IN INDONESIA.

Skilodimou, H.D. et al., 2018. Physical and anthropogenic factors related to landslide activity in the northern Peloponnese, Greece. Land, 7(3).

Shary, J. A., Sharaya, L. S., dan Mitusov. (2002). Fundamental Quantitative Methods of Land Surface Analysis. Geoderma, 1-32.

Tjahjono, Heri., Suripin., Kismartini. (2018). Community Capacity in the Face of Landslide Hazard Southern of Semarang City. ICENIS (pp. 1-7). Web of Science.

Zhang, Fanyu., Chen, Wenwu., Liang, Shaouyun., Chen, R., 2012. Human-induced landslide on a high cut slope: a case of repeated failures due to multi-excavation. Journal of Rock Mechanics and Geotechnical Engineering, 4(4), pp. 367-374.

Zuazo, V.H.D. \& Pleguezuelo, C.R.R., 2008. Soil-erosion and runoff prevention by plant covers. A review. Agronomy for Sustainable Development, 28(1), pp. 65-86. 